\title{
European Humanities in the Perception of Chinese Students: A Reflection Based on A Personal Teaching Experience
}

\section{Ionut Untea}

ORCID: https://orcid.org/0000-0003-2336-1389

(Southeast University, Nanjing; untea_ionut@126.com)

\section{Introduction}

As a young teaching and research fellow, after one year of teaching western philosophy in mainland China, while I cannot say that my enthusiasm has been curved, it is fair to admit that it has been challenged on several occasions. First of all, the way I had been teaching western ideas and aspects of society to a European public differed widely from the way I was expected to teach by my Chinese students. Having had Chinese students during my teaching at the University of La Rochelle in France helped me a lot for a first impression of what teaching in front of a classroom full of Chinese students would be, but it proved insufficient, given the completely different context: at Southeast University it is me the foreign professor, so I had to adapt my teaching to the Chinese cultural expectations.

A very important step in modeling my pedagogical message consisted in my attempt to understand several coordinates of my students' own cultural background. As I will show, beyond the language barrier, which generated a peculiar relation with students, rather different from what I had experienced in Europe when teaching in English, several specific cultural features, like the search for the pragmatic aspect in the approach to humanities, the value of personal excellence based on merit, combined with the deep respect for the role played by each person in society, greatly influenced the ways I was trying to establish connections, in my Chinese students' minds, between eastern and western philosophy and culture. Besides the challenges encountered, the experience with my colleagues and the discussions with students during classes proved revelatory for my advancement in the understanding of both the Chinese humanistic atmosphere and the students' approach to the European humanities.

I found that the perception of the European worldview in China seems almost as 
mythical as the perception of the Chinese worldview by students in Europe. This view came from a special perception of the role of the European humanities scholar as an intellectual engaged in the concrete societal issues and debates appearing at national and European level. I will conclude by arguing that the image the Chinese students have about western and European world, mainly under the influence of the Chinese cultural coordinates, has a deep relevance for the contemporary debates about the role of humanities in Europe. The kind of "pragmatic" role that humanities have in China in consolidating the feeling of belonging of all citizens, across social layers, may also be relevant for the debates surrounding European identity and integration, and the role of European humanities in the process of dealing with these issues.

\section{The Challenges of Being a „Foreign” Teacher in Mainland China}

When thinking about living and working in China, one of the first things that one expects to find hard o cope with is language. I confess having given up many times, and then started all over, to learn Chinese during my first year. At least showing that you are making efforts has a positive influence on the academic relationships with students, even though I could see smiles on their faces every time I was trying to pronounce a word, a phrase in Chinese, or even their names. Their smiles were kind, and every time they felt happy when I told them I understood a particular Chinese character or a particular phrase. The other way around, a serious barrier in the communication of my students with me was the English language. I felt many times that some of the excellent students were frustrated by not being able to express their thoughts completely. This frustration led to an interesting phenomenon: the students who rather mastered English fairly well were less likely to engage in conversation with the teacher, while the students whose level of English was rather low succeeded in communicating their thoughts with the help of other colleagues or searching in dictionaries. When good-leveled English students did engage in conversation, it was rather difficult to understand their point, since they tended to talk too much, in order to show their skills, while the less skilled students in communicating in English were more efficient in communicating their main idea. This means that both categories of students needed time to express their views, some just for identifying the keywords of their main thought, others to finish their very long sentences. Thus, it has been a challenge to conciliate the students' need for more time to express their thoughts, the time constraints in which I had to integrate my lectures, and the overall dynamic of the class, since I was not willing to let my philosophical class become a language tutoring module.

My effort to integrate both the students' linguistic needs and the requirements of my curriculum was further challenged from a methodological perspective, especially in the case of my course entitled History of Western Philosophy, which I taught for the undergraduates. The most basic issue that at first I simply couldn't understand, was why 
my students were continuously asking for more "information". So I would come up the following week with more philosophical details, but then they were still asking for more information. After about four weeks of teaching and wondering what they were actually asking for, a Chinese colleague pointed out that they were actually asking for historical information surrounding the historical figure of a philosopher, or the connection of that philosophy with historical events, and even more, a logical development of certain philosophical ideas into a different set of philosophical ideas in certain historical period. That is why they seemed rather uncomfortable to discover that the way I had chosen to present the "history" of philosophical ideas had not been quite chronological, or that I had chosen for instance to talk three times about the same philosopher in three different lectures dedicated to different philosophical topics. Simply put, they were interested both in what was "historical" in philosophy (how philosophical ideas actually stemmed from major historical events) and what was "philosophical" in history (the ideas and ideals that generated major social movements). Until then I had been accustomed not to place too much emphasis on the historical dimension of philosophy, especially because, as a scholar, it had never been my aim to engage critically with major philosophical eras or currents or to construct my own system of thought. Neither did I intend to have a "philosophy of history" class. But being in the position of a professor of history of western philosophy I realized that my students needed grand historical narratives and that they also needed my solutions as normative keys of interpretation.

What my students were expecting was not necessarily a historicist interpretation of philosophical reading, but rather the concrete connection of philosophy with history, and with everyday life, in virtue of the pragmatic spirit of the Chinese culture (Shusterman 2004). Although I included historical aspects in my lectures, I always cautioned them that, as simple students of philosophy, especially when we are dealing with introductory courses, we should be more modest. Our modesty in studying the "history" of modern western philosophy has been manifested by the continuous effort of trying to produce connections, comparisons, between philosophical ideas (basically of the late nineteenth century and early twentieth century) and critical discussions. They were rather dissatisfied at the end of the semester that I did not clearly define enough "concepts", and that, in spite of the rich and appealing content of my lectures, they learned so many philosophical questions, but did not receive as many answers. Of course, my appeal to modesty did not work too much, since my students considered that it was my "role" to give them answers.

It is not only the appeal to history that I learned to be useful during my classes in China but actually the appeal to cultural elements, to literature, art, ecology as the elements of the humanities that would satisfy the philosophical curiosity of my Chinese students. But even more challenging it was to connect the western with the Chinese humanities. I admit, I had known, and I still know very little about Chinese humanities, that is why every time I met them, especially making use of the attitude that I called "modesty," I provoked them to react to a western idea with what they thought it might be more or 
less similar in their cultural context. It is, indeed, part of the academic process, especially when teaching humanities to an audience not acquainted with basic western concepts, to model a kind of discourse that would absorb non-western elements in order to connect, at least superficially, the attention of my students to the world of the western mind.

A strategy of teaching I had been very good at with my European students, but which simply failed in China was to read the reactions appearing on my students' faces. Back in Europe, it had been relatively unproblematic to unfold a strategy of presenting my ideas in connection with the reactions I could see on the faces of my students. The biggest problem I would encounter in China was that I simply could not "read" a Chinese face. When several of my students knit their eyebrows I was inclined to take this gesture as a sign of distrust or misunderstanding, but actually it was their way to show a deep understanding. I would stop many times at the sight of this gesture, and ask, "is there something you do not agree with?" I would then have from these students some profound reflection that related to an idea that I wanted to place in the conclusions of my lecture. Sometimes my students would not even blink, showing me something that appeared to be just a cold face. This prompted me to start making large gestures, and even jumps, or role-taking discourses, to portray better some situations that may hide philosophical reflection. It seemed to me many times frustrating to feel as if I had a classroom full of terracotta soldiers like those in Xi'an.

\section{The „Use" of Western Humanities for the New Generation of Chinese Students}

As I already mentioned, when hearing about my students' expectations for more historical elements in my "History of Western Philosophy" class, I was initially tempted to think that they were rather inclined towards a historicist understanding of the history of philosophy. Nonetheless, when reevaluating this demand against the traditional cultural background in China, I understood my students' need for a connection of the philosophical study - and actually a connection of humanistic studies in general-not only with history but also with society and its everyday life. ${ }^{1}$ Actually very early at the beginning of my teaching, during a short break, one student came to me and asked me candidly: "Teacher, please excuse me for asking, but why do we, as Chinese students living in China, need to know about western philosophy?"

This question seemed so odd because it came from a student far from lazy, who actually, in the end, would get one of the highest grades in her class. The question was nevertheless not about the usefulness of humanities in general, but about the use of "western," and more specifically "European," humanities in China. Her thirst for applying the study of humanities in her concrete environment fascinated me. I met the same intellectual proclivity in my MA students, to which I taught two modules, Intercultural

1 For the Chinese cultural characteristics of discovering humanity in practical activities of everyday life, see Tu Weiming $(1997,52)$. 
semiotics and Aesthetics of everyday life. I had read that Chinese students are usually full of imagination (Stone 2016) and during my experience in teaching to them, this seemed to be one of the dominant features. Nevertheless, their creativity blossomed especially when the content of my lectures, mainly focused on a selection of elements from western humanities, was connected to the content of Chinese humanities. At the end of the semester, the MA students wrote great value essays making connections between western and Chinese culture that greatly enriched my horizons. For instance, I had papers focusing on Chinese feminism and the traditional perception of women, on sexual desire, or on the philosophical implications of the Chinese term "relationship" (guanxi) and how this could be perceived in the west. I also had papers on the ghost culture in China and the west, on the cultural and philosophical connotations of Chinese folk paper-cut, and even philosophical interpretations of the relationships between traffic signs and symbols with the real-life situations of the Chinese urban traffic. Other papers focused on the ways commodities are perceived in China in the economic process, others connected the Chinese culture of "filial piety" with the modern pension system, inspired by western values, and others even attempted to identify features of cynicism in the Chinese and western societies.

In all these papers, there was a transparent effort toward a connection with Chinese everyday life, and many times we would surpass the allotted time given for the class, with the risk of letting my students go to the dining hall too late for lunch or dinner (my classes with the undergraduates usually finished before lunch, while with graduates before dinner). During the whole year I made efforts to overcome an interesting phenomenon: during my first hour or so it was very hard to get my students to talk, but once in movement, I could not stop them. One of the explanations may consist in their ambition to find a "useful" aspect of western ideas that could help them think more about and with the tools of the Chinese philosophy and culture. Establishing such bridges has not always been an easy task.

An important opportunity, to find out more why my Chinese students placed such a high emphasis on the "use" of humanities, came with my lecture dedicated to philosophical pragmatism. Since then we would talk about what makes the characteristics of Chinese pragmatism. It was then easier to identify in my students' attitude a "pragmatic-Confucian phenomenology" as described by Robert Cummings Neville:

Pragmatic Confucians do not expect victory, only the opportunity to do the best we can on our watch, educated to appreciate both the vast and deep values as well as the pervasive injustices in our environment. Philosophy is not just for description but for learning to appreciate and renovate (Neville 2015, 211).

In order to bring in front of my eyes a comprehensive image of the pragmatic approach to humanities in the Chinese culture, my students took me on an imaginary journey encompassing aspects of ancient China, features of social philosophy "with Chinese characteristics," the contemporary "Chinese dream" slogan, and the social ideals 
of contemporary youth. It would seem too simplistic to equate with nationalism my students' emphasis on the application of humanities to Chinese realities. Rather, in virtue of the vast culture and history of China, they were indeed animated by a special pride of being the inheritors of the Chinese identity. Even the student who initially asked me the question about the "use" of western humanities made explicit that western humanities should be made compatible with the Chinese identity, not the other way around.

\section{The Culture of Meritocracy and "the Way of Life"}

My previous experience of teaching in France had made me discover that it was a good thing to tell students that they should not worry while speaking English in front of me, because I was not a native English speaker anyway, so I could understand their hesitations and will not be hasty to penalize them only for this. Nevertheless, this did not work in China, mainly because of the students' unwillingness to speak when they felt less capable of producing excellent opinions, both in form and content. At the University of La Rochelle, where I had my first experience as a teacher in front of Chinese students, I had perceived them as very eager to talk, always occupying the first row, and always raising their hands. Many times, the Chinese students in La Rochelle fared better than many of the French students, but always stuck together during classes, a fact which I pointed out during my lectures. I advised both French students to make place for the Chinese students among them, and Chinese students to feel relaxed when sitting among their European companions. Although outside classroom Chinese and French students did communicate very well and did engage in common extra-curricular activities, when it came for in-class activities, the Chinese students rather tended to group together. My personal explanation for this curious situation was that outside classroom, the Chinese exchange students needed to socialize, learn better French, make new international friends and adopt new perspectives on the society they were beginning to explore. In contrast, in classroom they only wanted to focus on learning from what their teacher had to communicate, as they wanted to fully concentrate on the teacher's message while not being distracted by the attitudes of their foreign colleagues. Thus, creating, at least artificially, a small milieu of students from their same culture helped them feel ready for a competitive learning process.

During my teaching activity in Nanjing, in mainland China, I remembered this feature of my La Rochelle Chinese students, but at the same time I discovered at least two more aspects of this strive for excellence. First of all, the ones who raised their hands were not the ones who mastered English very well, but simply those who wanted to have a chance to express their thoughts. In contrast, the students who mastered English fairly well did not dare to speak, as they felt that their level of English was still very low, and that their original thought in Chinese would suffer. I realized then that the Chinese culture of meritocracy could be at times a conversation starter, and at times a conversation stopper 
(Liu 2006, 12). While I saw many times their struggle for achievement as a good thing, since many students challenged themselves and asked their questions, in spite of their low skills in communicating their thoughts in English, sometimes the students that could express themselves much easier refused to do so, in order to avoid their colleagues' or teacher's laughing at their "Chinglish."

Another aspect of the culture of meritocracy that I discovered during my teaching was the fact that I was being myself assimilated by my students with the meritocratic society, an aspect I had never thought about before. In virtue of this special position that I had been assigned, I was expected to behave in a certain way (that actually I was never aware of) when giving my lectures. For instance, I was expected to nominate the students who were supposed to talk. That is why many times I discovered students who had very interesting things to say, but never manifested themselves, until I nominated them. Others simply did not talk because they did not want to interrupt me. Not being aware of how I should have behaved, I was rather surprised when one of my colleagues informed me that, after a student evaluation at the end of the semester, my undergraduates in western philosophy agreed that they had learned about so many new philosophical questions from their new teacher, but the teacher actually did not give them enough "answers." As a scholar of philosophy formed in the western tradition, this sounded like a praise, but actually it was a negative point. In my students' perception, I had not fully performed the duty assigned to my role.

My graduate students helped me understand more about the Chinese culture of meritocracy, and introduced me to the vision of "the way things are," as they called it, in the traditional and contemporary Chinese society. As the notion of "individual," with which a westerner is so familiar, is rather absent in the Chinese culture, the "self" is created via a web of tasks and duties relevant to the places occupied by somebody in specific milieus. Although one's place in society is never fixed, because in principle anybody has the opportunity to achieve an ascendant path by personal merits, once a place is occupied by somebody, then she or he must prove worthy of the position acquired. Everybody has a "dao," a role, a place and way of life, which should not be understood in an individualistic manner, but as a way of life that generates the excellence of the person who gives content to the position occupied ( $\mathrm{Zi} \mathrm{2016).} \mathrm{This} \mathrm{is} \mathrm{indeed} \mathrm{not} \mathrm{far} \mathrm{from} \mathrm{a} \mathrm{pragmatic} \mathrm{view,} \mathrm{but} \mathrm{in} \mathrm{a}$ Chinese context it is much more than mere pragmatism: it is the way the self reflects and is defined by the intricate relationships of family, society, or by the person's social and political identity.

\section{The Humanistic Atmosphere, the Culture of Wisdom and the Perception of the European Humanities}

During my classes, I talked with my students about the importance of wisdom in the Chinese culture. We also talked about the role of wisdom in the Chinese and European 
humanism, with many of them crediting European humanism for important historical advancements with universal reach regarding the attention given to the human self and its potential development. Nevertheless, the majority agreed that, although the European humanistic perspective brought Enlightenment to the whole world, they felt there was a need for what they called a "post-Enlightenment humanism," in which cultures that had been regarded as peripheral would have an important saying in the way human personality is acknowledged universally. One model for my students' view has been the contemporary Confucian philosopher Tu Weiming. We discussed his perspective, laid down in several of his internationally praised works, by reading some excerpts during classes. For instance, in Centrality and Commonality: An Essay on Confucian Religiousness, Tu Weiming proposes the concept of "inclusive humanism" that stresses both the comprehensive character of humanity in Confucianism and delimitates itself from several forms of "exclusive secular humanism". Tu argues:

One becomes fully human within a community. (...) The preferred course of action is to integrate all levels of the community (family, neighborhood, clan, race, nation, world, universe, cosmos) into the process of self-transformation. The Confucians believe that this gradual process of inclusion is inherent in the project of learning to be fully human (Tu 1989, 97).

It is not a coincidence that the 2018 edition of the World Congress of Philosophy, which took place in Beijing, has been entitled "Learning to be Human," upon Tu Weiming's suggestion, who launched in 2013 the initiative for the organization of the twenty-fourth edition at Peking University, where he is currently teaching. ${ }^{2}$

Going back to my discussions with the students at Southeast University, I was particularly impressed by their perception of the European humanistic intellectuals of contemporary Europe. As I mentioned already, their views have been consolidated by both a pragmatic view, and a view on the special role that, once accepted by somebody, it needs to be accomplished in an excellent way. This led my Chinese students to have an image almost as exotic about the European humanistic culture, as European students and scholars have about the Chinese world: from their participation to the discussions, an interesting image of the European humanities intellectual emerged, one of a thinker engaged in the concrete social, political, and cultural life of both Europe as a whole and of each European nation. As my students have been thirsty to know about the role of historical circumstances in the formulation of ideas by certain philosophers, now they were curious to know about the concrete contemporary reactions of the European public to intellectual ideas, or about the public engagement of intellectuals in some of the most diverse publicly debated topics like Brexit, the wave of migrants that has overwhelmed European shores since 2014, the intellectual reactions to Umberto Eco's death, the yw/welcome/index.htm (accessed on June 20, 2018). 
implications of the scandal of the burkini, and not the least, the election in France of Emmanuel Macron, a president who studied philosophy in university.

From the point of view of my Chinese students' aspirations toward knowledge and personal philosophical fulfillment, the European world remains probably as mythical as the Chinese world seems for the European student. Some of my students intend to enroll in European universities, at least for short-term programs, in order to come closer to the understanding of the role of the European humanities in the education of not only the intellectual but also of the average people. They are more fascinated about how ordinary people interact with culture because they want to bring at home new insights and new perspectives on how to assimilate modernity without negating traditional values. Many of my students expressed their disappointment on the preferences of the young and younger generations in China for imported habits and fashionable attitudes, a tendency that engendered the marginalization of what they saw as the attitude of the integration of Chinese and western humanistic values, trends and behaviors in a coherent whole. From this point of view, I suggest that the future generation of philosophers in China may feel closely connected to the Confucian ideal of what Tu Weiming called a "fiduciary community," which is conceived as a "society of mutual trust instead of a mere aggregate of individuals" and which promotes "human relatedness," as its members "cultivate their own personal characters" (Tu 1989, 56). The students I discussed with hoped to come back home after experiencing the European practice of humanistic disciplines in order to integrate this experience into their space of identity where, in the Confucian perspective, the whole community is mirrored in one person, and where the self is the medium where family and social ties are intimately connected.

What my students were worried about was the possible refusal by future generations to see and look for the concrete nourishment of the Chinese identity by the culture of humanities and arts. Until now, older generations have successfully cultivated this intimate connection, irrespectively of their level of literacy. I could indeed observe this myself, especially in Shanghai and Nanjing: for instance, nearly all taxi drivers listen to classic audio-books about Chinese culture and history while doing their job; the average worker while eating in a cheap restaurant watches on his cell phone public lectures of famous Chinese scholars; retired women gather in parks to rehearse dance moves inspired by Chinese traditional songs and occasionally give public representations dressed in traditional garments. Moreover, every morning and every evening one could see many people of all ages rehearsing Tai Chi moves in order to cultivate a healthy mind in a fit body. Even illiterate women and men cultivate their minds by sounds, listening to Chinese traditional opera, or visually by playing the complicated Chinese chess game. When meeting some friends in Shanghai, they introduced me to the practice of calligraphy, telling me that the average child does this in China, as it is not only a writing exercise but a way to educate the whole body and spirit. These are only a few examples that show how seriously average people in China rely on the role of humanities and the arts on their 
everyday life.

\section{Conclusions}

My experience in teaching western philosophy to mainland Chinese students has only been possible thanks to an institutional flexibility at Southeast University to allow foreign professors to teach in English. In spite of the administrative ups and downs, because the language of all administrative documents is Chinese, I have been actually impressed that my proposal for an MA course has been accepted fast if compared with the lengthy administrative process to introduce a new course in the curricula of European universities. Moreover, the willingness to introduce Chinese students to programs taught in English may only have the positive result of opening up their intellectual horizons. Even at the level of the Chinese society, at least as I observed in Nanjing and Shanghai, there is a willingness to display public announcements in English alongside the ones in Mandarin. In spite of my feelings of frustration that these announcements are sometimes written in bad English, or simply have no meaning, the effort of opening up at least the Chinese urban culture to foreigners is there, and progress is being made. The same is true for the administrative duties in Southeast University, as sometimes the administrative officers simply learn to do some tasks for the first time when dealing with my profile, as I am among the few foreign professors hired by the School of Humanities. Learning comes with practice, for me as a foreign professor, for my students, for the administrative officers, and for my colleagues offering me help and advice.

By giving me a lower teaching load than that of my Chinese counterparts, the School of Humanities took indeed into consideration my new challenges stemming from my position as a foreign professor, allowing me more time to get acquainted with the Chinese language and society, or to prepare my lectures involving a higher level of information, given the extraordinary curiosity of my students about the western humanities. Moreover, in the context of the primacy of relations on the human level, right from the moment of the Skype interview, I felt that I would like to work with the Faculty team at Southeast University, and the feeling has been mutual, since they allowed me, a rather young and not a very experienced researcher and professor to come to Nanjing. Before the interview, I knew about the very high Chinese standards regarding publications in top-level international journals, a detail I had not been sufficiently aware of while doing research or teaching in Europe. I took as an encouragement the fact that I was nonetheless accepted for the position, and indeed the School's trust in my capacities proved right. It is rarely the case in western countries for the hiring committees to give this kind of chance to young scholars. I still receive newsletters with calls for job applications in the UK and European universities, and I am astonished at the trends in recruiting researchers in the same way entrepreneurs are, the focus being rather on the experience in securing what it is called "external funding." This can be very frustrating for the young competitive 
postdoctoral scholar, with a great potential and capacities, but with less institutional experience.

As the circulation of young researchers in humanities within Europe is still relatively possible, given the existence of independent postdoctoral grants and research fellowships, many European states have their own national rigid structures of recruiting academics, which in practice keep outside the system many extraordinary skilled foreign teachers. At the European level, heads of state are debating about the professional qualifications of workers, and exchange of temporary workers between European countries, or about the impact of the migrant crisis on European identity and the raising populism, but rather political or legal solutions have been discussed, at the expense of educational and cultural solutions. A willingness at the EU level to make more flexible, and more inclusive, the rather rigid national systems in education will only have a positive and more lasting impact on the European integration and its identity. Of course, results cannot be achieved over-night, as in the case of solutions of a political character.

My Chinese experience showed me that, on a society that has so high esteem for humanities across social layers, the voice of the young generation of future Chinese intellectuals may represent an excellent source of reflection on what it means to be a humanities scholar in Europe. My students' call for a more pragmatic approach to humanities is deeply rooted in the societal need of finding a "use" of humanities in the everyday life even by the average person. This is unlikely to be the case in Europe, where even at the highest level of recruiting professionals in humanities what matters first is obtaining funds for the universities. The intimate link between humanities and identity proved important in China across millennia. European Union needs to be accepted in the minds of peoples of different nationalities that it is much more than an economic union. While this goal is still beyond our foreseeable common European future, some leaders of national states and parties will continue absorbing European funds, while encouraging ultra-nationalistic discourses.

My Chinese students' fascination for the European world, as a space where intellectuals, in virtue of their privileged "role," are engaged in the concrete evolutions of policies, and are connected via ideals of pedagogical formation to the mental imaginary of the average EU citizens about the European identity, is for the most part mythological. Nevertheless, their views and expectations regarding the European humanistic scholars are a reminder that the European identity is neither something simply reserved for the isolated intellectual, nor can it be achieved only by policies. The European average citizen needs to meet frequently with foreign teachers in kindergartens, schools, high-schools and universities during her or his lifelong education, as these meetings may open up horizons not only in their specific national cultures, but also for a wider European culture, and beyond.

The European identity is much more than the pride of being the top region of the free world. Indeed, other countries are catching up in the advancement of the value given 
to the human being and the promotion of European-inspired universalist ideas, while Europeans are becoming more and more ultra-nationalistic. What makes us Europeans is more than the privileged economic ties or the space where people can circulate only on the basis of their identity card and where they can receive social welfare. Europe needs a deeper rooted identity of the average citizens and needs to display to newcomers some credible, trustworthy and creative ways of connecting to the past or to the present diverse cultural heritages, in order to coherently orient their collective and individual aspirations towards the future.

\section{Literature}

Lao Zi. 2016. Tao Te Ching (transl. James Legge). Zheng Zhou: Zhongzhou Ancient Books Publishing House.

Liu Ye. 2016. Higher Education, Meritocracy and Inequality in China. Singapore: Springer.

Neville R. C. 2015. „Value And Selfhood: Pragmatism, Confucianism, and Phenomenology.” Journal of Chinese Philosophy 42(1-2): 197-212.

Stone D. 2016. „Reflection on Teaching the Humanities in China,“ in E. T.Y. Chan \& M. O'Sullivan (Eds.), The Humanities in Contemporary Chinese Contexts. Singapore: Springer Nature (133-42).

Shusterman R. 2004. „Pragmatism and East-Asian Thought.“ Metaphilosophy 35(1-2):1343.

Tu W. M. 1989. Centrality and Commonality: An Essay on Confucian Religiousness. Albany: State University of New York Press.

Tu W. M. 1997. Confucian Thought: Selfhood as Creative Transformation. Albany: State University of New York Press.

World Congress of Philosophy. 2018. Official Website. http://wcp2018.pku.edu.cn/yw/ welcome/index.htm. 


\title{
Ionut Untea (Nanjing)
}

\section{European Humanities in the Perception of Chinese Students: A Reflection Based on A Personal Teaching Experience}

\begin{abstract}
As a young teacher and researcher, the prospective of introducing western philosophical themes to a public of students from a non-western country, came in 2016 as a once-in-a lifetime opportunity, which I met with great enthusiasm. However, as in any situation involving pre-conceived expectations, facing and dealing with the real situation on the ground opens up a pathway for a closer understanding of both the new culture explored, a perception of one's own limits and the willingness to overcome them. The following lines are intended to cover the way my approach to teaching to a Chinese public has evolved from pre-conceptions and empty enthusiasm to an attitude of pedagogical creativity in identifying and presenting the key topics that would attract my students' attention. As I will show, students' expectations were to approach the western ideas not directly, but via a more complex process of being acquainted with the major historical and cultural movements in Europe and the western world. This meant the involvement in the teaching process of a wider number of elements taken not only from philosophy but from other humanistic disciplines.
\end{abstract}

Keywords: humanities; Chinese identity; European identity; personal teaching experience.

Ethics in Progress (ISSN 2084-9257). Vol. 10 (2019). No. 1, Art. \#4, pp. 41-53.

Creative Commons BY-SA 4.0

Doi:10.14746/eip.2019.1.4 